\title{
Differential distribution of heparan sulfate glycoforms and elevated expression of heparan sulfate biosynthetic enzyme genes in the brain of mucopolysaccharidosis IIIB mice
}

\author{
Douglas M. McCarty • Julianne DiRosario • \\ Kadra Gulaid • Smruti Killedar • Arie Oosterhof • \\ Toin H. van Kuppevelt • Paul T. Martin • Haiyan Fu
}

Received: 1 October 2010 /Accepted: 21 December 2010 /Published online: 12 January 2011

(C) The Author(s) 2011. This article is published with open access at Springerlink.com

\begin{abstract}
The primary pathology in mucopolysaccharidosis (MPS) IIIB is lysosomal storage of heparan sulfate (HS) glycosaminoglycans, leading to complex neuropathology and dysfunction, for which the detailed mechanisms remain unclear. Using antibodies that recognize specific HS glycoforms, we demonstrate differential cell-specific and domain-specific lysosomal HS-GAG distribution in MPS IIIB mouse brain. We also describe a novel neuron-specific brain HS epitope with broad, non-specific increase in the expression in all neurons in MPS IIIB mouse brain, including cerebellar granule neurons, which do not exhibit lysosomal storage pathology. This suggests that biosynthesis of certain HS glycoforms is enhanced throughout the CNS of MPS IIIB mice. Such a conclusion is further supported by demonstration of increased expression of multiple genes encoding enzymes essential in HS biosynthesis, including HS sulfotransferases and epimerases, as well as FGFs, for which HS serves as a co-receptor, in MPS
\end{abstract}

D. M. McCarty · J. DiRosario · K. Gulaid · S. Killedar •

P. T. Martin · H. Fu $(\bowtie)$

The Center for Gene Therapy, The Research Institute at

Nationwide Children's Hospital, The Ohio State University,

700 Children's Drive,

Columbus, $\mathrm{OH} 43205$, USA

e-mail: haiyan.fu@nationwidechildrens.org

D. M. McCarty $\cdot$ S. Killedar $\cdot$ P. T. Martin $\cdot$ H. Fu

Department of Pediatrics, College of Medicine and Public Health,

The Ohio State University,

700 Children's Drive,

Columbus, $\mathrm{OH} 43205$, USA

A. Oosterhof $\cdot$ T. H. van Kuppevelt

Department of Biochemistry, Nijmegen Center for Molecular Life Sciences, Radboud University Nijmegen Medical Center, 6500 HB, Nijmegen, The Netherlands
IIIB brain. These data suggest that lysosomal storage of HS may lead to the increase in HS biosyntheses, which may contribute to the neuropathology of MPS IIIB by exacerbating the lysosomal HS storage.

Keywords MPS IIIB $\cdot$ Lysosomal storage disease $\cdot$ Heparan sulfate $\cdot$ Neuropathology $\cdot$ Glycobiosynthesis

\section{Introduction}

Heparan sulfates (HS) are a class of biologically important glycosaminoglycans (GAGs) that serve as major functional components of proteoglycans (PGs). Virtually every type of animal cell has the capacity of HS biosynthesis. Heparan sulfate proteoglycans (HSPGs) reside on the membrane of all animal cells and in extracellular matrices and intracellular components. HSPGs participate in various biological processes as receptors or co-receptors for protein ligands, including growth factors, cell adhesion molecules, morphogens, cytokines/chemokines, enzymes/enzyme inhibitors, and extracellular matrix proteins (Esko and Selleck 2002). After ligand binding and signaling have occurred, most transmembrane HSPGs are targeted for degradation by endocytosis and subsequent transport to and degradation in the lysosome (Freeze 2008; Varki et al. 2008). In the lysosome, glycosidases remove individual monosaccharides from the long GAG glycan chains. Monosaccharides are then typically exported from the lysosome into the cytoplasm to reenter new cycles of protein or lipid glycosylation (Varki et al. 2008).

Mucopolysaccharidosis (MPS) IIIB is an inherited lysosomal storage disease caused by the autosomal recessive defect of $\alpha$-N-acetylglucosaminidase ( $\mathrm{NaGlu}$ ) gene, 
coding for a lysosomal enzyme essential in the metabolic degradation of HS-GAGs (Neufeld and Muenzer 2001). Genetic mutations are highly heterogenic among patients with MPS IIIB (Neufeld and Muenzer 2001; Yogalingam and Hopwood 2001). The lack of NaGlu activity disrupts the stepwise enzymatic reaction for GAG degradation, resulting in the accumulation of HS and HS-derived oligosaccharides in lysosomes of cells in virtually all organs, especially cells throughout the central nervous system (CNS), including neuronal and non-neuronal cells, although not all CNS cells are affected (Li et al. 1999). Patients with MPS IIIB appear normal at birth, but develop progressive and severe neurological disorder, while somatic manifestations of MPS IIIB are relatively mild compared to other types of MPS (Neufeld and Muenzer 2001). The profound neurological manifestation causes the high mortality in MPS IIIB patients. The establishment of knock-out mouse model of MPS IIIB that resembles the human disease has offered an invaluable tool for studies on the disease mechanisms and therapeutic development ( $\mathrm{Li}$ et al. 1999).

No treatment is available for MPS IIIB. However, the by-stander properties of lysosomal enzymes have led to the success of recombinant enzyme replacement therapy and hematopoietic stem cell transplantation which have been used to treat patients with MPS I, II and VI, with somatic benefits (Sands and Haskins 2008). MPS IIIB and other lysosomal storage disorders with the CNS manifestations are not amenable to enzyme replacement or stem cell therapies because of the presence of the blood brain barrier (BBB), which blocks entry of such therapies into the CNS. Viral vector-mediated gene therapy approaches have been developed for long-term restoration of the enzyme activities in the CNS to treat the neurological disease of MPS IIIB and other lysosomal storage disorders (Sands and Haskins 2008). While showing significant functional neurological benefits, these gene therapy approaches did not yield a cure in animal models of these diseases. Many studies have shown that efficient expression of recombinant enzymes leads to the reduction, but not the clearance, of lysosomal storage pathology in animal models after therapeutic gene delivery, despite high level expression of recombinant enzyme activity (Cearley and Wolfe 2007; Cressant et al. 2004; Desmaris et al. 2004; Fu et al. 2002, 2007, 2010; Heuer et al. 2002; Kurai et al. 2007; Liu et al. 2005; McCarty et al. 2009; Sferra et al. 2000; Zheng et al. 2004). These suggest that developing a cure for the CNS diseases of MPS IIIB and other similar disorders may require more than the simple restoration of the absent or deficient lysosomal enzyme activity. This is supported by recent studies demonstrating a complex multifactorial contribution to the neuropathology of MPS IIIB, secondary to the primary pathology- the lysosomal storage of HS and HS- derived GAGs (DiRosario et al. 2009; Killedar et al. 2010; Li et al. 2002; McGlynn et al. 2004; Ohmi et al. 2003, 2009; Ryazantsev et al. 2007; Villani et al. 2007; Walkley 2007). The complex neuropathology of MPS IIIB has been shown to involve impaired metabolisms, inflammation, neurodegeneration, reactive oxygen species and tauopathy. A recent study reported the correlation between the high efficiency of GAG synthesis and a severe phenotype in patients with MPS, including MPS II, IIIA and IIIB (Piotrowska et al. 2009). Further, strategies aimed at reducing the accumulation of substrates for deficient lysosomal enzymes, have shown therapeutic benefits or potential in fibroblasts or mice with MPS IIIA, IIIB, by inhibiting GAG synthesis using chemical inhibition or gene silencing (Beck 2007; Dziedzic et al. 2010; JakobkiewiczBanecka et al. 2009; Kaidonis et al. 2010; Malinowska et al. 2009; Roberts et al. 2006, 2007). These data suggest that the lysosomal storage pathology may induce the impairment of glycosylation and/or GAG synthesis.

In this study we describe the accumulation of specific HS glycoforms in the CNS of the MPS IIIB mouse model and demonstrate differential distribution patterns of different HS moieties. In addition, we demonstrate broad increases in certain HS structures throughout MPS IIIB brain, coupled with increased expression of HS biosynthetic enzymes. These data suggest the importance of specific HS glycoforms in the neuropathology of MPS IIIB and also support a contributing role for elevated HS biosynthesis in the disease.

\section{Materials and methods}

\section{MPS IIIB mice}

The MPS IIIB mouse model, generated by homologous recombination (Li et al. 1999), was maintained on an inbred background (C57BL/6) of backcrosses of heterozygotes. The MPS IIIB mice resemble the human disease, have no detectable NaGlu activity in any tissue, and exhibit characteristic lysosomal storage pathology and clinical disorders. The mice were housed in the Vivarium at the Research Institute at Nationwide Children's Hospital (NCH-RI). All care and procedures were in accordance with the Guide for the Care and Use of Laboratory Animals [DHHS Publication No. (NIH) 85-23. The genotypes of progeny mice were identified by PCR, using primers targeting mNaGlu Exon 6: 5'-TGGACCTGTTTGCTGAAAGC (sense) and 5'CAGGCCATCAAATCTGGTAC (anti-sense), or the transgene (neomycin): 5'-TGGGATCGGCCATTGAACAA (sense) and 5'-CCTTGAGCCTGGCGAACAGT (antisense). Wild type (wt) littermates of MPS IIIB mice were used as controls in all instances. 
Tissue sample preparation

For tissue sample collection, age-matched MPS IIIB and wt mice were anesthetized with an intraperitoneal injection of avertin $(2.5 \%, 0.3-0.4 \mathrm{mg} / \mathrm{g}$ body weight), and were then perfused transcardially with cold PBS $(0.1 \mathrm{M}, \mathrm{pH} 7.4)$. The entire brains of the mice were collected. Each brain was divided into two halves along the midline, with each hemisphere used for different assays. Tissue samples were placed on dry ice or embedded in OCT compound and stored at $-70^{\circ} \mathrm{C}$ before being processed for analyses.

Anti-HS antibodies and immunohistochemical localization of HS

The anti-HS antibodies used in this study (HS4E4, EV3C3, HS4C3, AO4B08 and RB4Ea) were generated using the phage display technology as described previously (van Kuppevelt et al. 1998, 2001) and were selected for reactivity against HS with different sulfation patterns, which are summarized in Table 1 (Dennissen et al. 2002; Kurup et al. 2007; Rops et al. 2008; Ten Dam et al. 2006). These antibodies contain a vesicular stomatitis virus Glycoprotein (VSV-G) tag for detection (van Kuppevelt et al. 1998)]. An irrelevant antibody, MPB49, also contains a VSV-G tag, was used as control (Lensen et al. 2005; Rops et al. 2008).

Immunofluorescence was performed to probe HS on coronal cryostat brain sections $(10 \mu \mathrm{m})$. After the incubation in blocking buffer, PBS-TT $(0.1 \%$ Tween-20, $0.1 \%$

Table 1 HS modifications involved in antibody binding

\begin{tabular}{|c|c|}
\hline Anti-HS antibodies & HS modifications for antibody binding \\
\hline \multirow[t]{3}{*}{ HS4E4 } & $N$-sulfation \\
\hline & $N$-acetylation \\
\hline & C5-epimerization \\
\hline \multirow[t]{4}{*}{ HS4C3 } & $N$-sulfation \\
\hline & $2-O$-sulfation \\
\hline & 6-O-sulfation \\
\hline & 3-O-sulfation \\
\hline \multirow[t]{3}{*}{ EV3C3 } & $N$-sulfation \\
\hline & C5-epimerization \\
\hline & 2-O-sulfation \\
\hline \multirow[t]{4}{*}{ AO4B08 } & $N$-sulfation \\
\hline & C5-epimerization \\
\hline & $2-O$-sulfation \\
\hline & 6-O-sulfation \\
\hline \multirow[t]{3}{*}{ RB4EA12 } & $N$-acetylation \\
\hline & $N$-sulfation \\
\hline & 6-O-sulfation \\
\hline
\end{tabular}

Triton-X-100, $\mathrm{pH}$ 7.4) containing $2 \% \mathrm{BSA}$, for $30 \mathrm{~min}$ at room temperature, the sections were then incubated with the above anti-HS antibodies (1:1 in blocking buffer) overnight at $4{ }^{\circ} \mathrm{C}$. The sections were washed three times with PBS-TT and then incubated with a mouse anti-VSV-G monoclonal antibody (Sigma-Aldrich, V5507) diluted 1:200 in blocking buffer for $60 \mathrm{~min}$ at room temperature. The bound antibodies were detected with a goat-anti-mouse IgG conjugated with AlexaFluo568 (Invitrogen). Although co-staining for neuronal and glial markers was not performed, the sizes and morphological features of brain parenchymal cells allowed us to determine the nature of the involved brain cells. The intensity of the IF signals were analyzed by manual thresholding using Image $J$ software (Abramoff et al. 2004).

\section{Quantitative real time PCR}

Total RNA was isolated from whole, dissected, brain hemispheres using the SV Total RNA Isolation System (Promega), following the manufacturer's protocols. The isolated total RNA samples were then further purified through an RNeasy spin column (Qiagen). RNA content and quality was assessed using a ND-1000 spectrophotometer.

Individual mouse brain total RNA samples were tested by qRT-PCR for the expression of multiple genes involved in HS biosynthesis, including $N$-deacetylase $N$-Sulfotransferase 1-4 (NDST1, 2, 3, 4), GlcA C5 Epimerase (GLCE), fibroblast growth factor 1 and 2 (FGF-1 and FGF-2). The sequence-specific primers were designed based on Entrez gene sequences and the requirements of reagent suppliers (Table 2). A pair of primers for murine GAPDH (glyceraldehyde-3-phosphate dehydrogenase) gene was used as internal control. Superscript ${ }^{\mathrm{TM}}$ First-strand Synthesis System for RT-PCR (Invitrogen) was used for cDNA synthesis. The qRT-PCR was performed using SYBR ${ }^{\circledR}$ Green PCR Master Mix (Applied Biosystems). Comparative threshold $\left(\mathrm{C}_{\mathrm{T}}\right)$ method was used for data analysis. Data were expressed as relative quantitation of gene expression $\left(2^{\wedge-\Delta \Delta C t}\right)$ in the brain of MPS IIIB vs. wt mice (Livak and Schmittgen 2001).

\section{Protein isolation and Western blotting}

Protein extraction and Western blotting were performed following established procedures. Whole-cell proteins were extracted from each whole mouse brain hemisphere samples. Protein was measured using a modified Bradford assay and identical amounts of whole cell protein were loaded and separated by SDS-PAGE, and then immunoblotted after transfer onto nitrocellulose using a semi-dry electrotransfer device (BioRad). The membranes were probed using primary antibodies against FGF-1 (Santa 
Table 2 Primer sequences for qRT-PCR

\begin{tabular}{|c|c|c|c|}
\hline Gene symbols & Gene names & GeneBank accession \# & Primer sequences \\
\hline NDST1 & $\mathrm{N}$-deacetylase/N-sulfotransferase 1 & NM_008306 & $\begin{array}{l}\text { F: 5'-TGCTCTGTGTGATCTGAGGCTAG-3' } \\
\text { R: 5'-GATATCAAGCCCACAGCCAGAC-3' }\end{array}$ \\
\hline NDST2 & $\mathrm{N}$-deacetylase/N-sulfotransferase 2 & NM_010811 & $\begin{array}{l}\text { F: 5'-AAGTCTTAGAGCAGAACCCAC-3' } \\
\text { R: 5'-ACTATGGGAAAGAGATGGATC-3' }\end{array}$ \\
\hline NDST3 & $\mathrm{N}$-deacetylase/N-sulfotransferase 3 & NM_031186 & $\begin{array}{l}\text { F: 5'-AGCTAACAACCAAAGTCACAG-3' } \\
\text { R: 5'-CCTATCAGAGGCAAAAGGATG-3' }\end{array}$ \\
\hline NDST4 & $\mathrm{N}$-deacetylase/N-sulfotransferase 4 & NM_022565 & $\begin{array}{l}\text { F: 5'-ACCCTCTCTGGCAGCGAAATTG-3' } \\
\text { R: 5'-GTTCCCTGTTCCAGATAGGTAG-3' }\end{array}$ \\
\hline GLCE & glucuronyl C5-epimerase & NM_033320 & $\begin{array}{l}\text { F: 5'-TGGTTTGGTTCACTTCTCTGAG-3' } \\
\text { R: 5'-AACTCCTAAAGGTCAAACCTGC-3' }\end{array}$ \\
\hline FGF1 & fibroblast growth factor 1 & NM_010197 & $\begin{array}{l}\text { F: 5'-GAACCTCACCAAAAGCTTTCTC-3', } \\
\text { R: 5'-GTTTCTAATTTGCTGGGCACTTG-3', }\end{array}$ \\
\hline FGF2 & fibroblast growth factor 2 & NM_008006 & $\begin{array}{l}\text { F: 5'-GAGTGTTTCTTCTTTGAACGAC-3' } \\
\text { R: 5'-GAGTTTATACTGCC AGTTCG-3' }\end{array}$ \\
\hline GAPDH & glyceraldehyde-3-phosphate dehydrogenase & NM_008084 & $\begin{array}{l}\text { F: 5'-CACTGAAGGGCATCTTGGGCTACAC-3' } \\
\text { R: 5'-TTGGAGGCCATGTAGGCCATGAGGT-3' }\end{array}$ \\
\hline
\end{tabular}

The sizes of the qRT-PCR products are 105-120 bp

Cruz) and FGF-2 (Upstate), followed by HRP-conjugated secondary antibodies (Sigma), and developed with ECL chemiluminiscent substrate (Pierce).

\section{Results}

Differential CNS distribution of HS glycoforms and cellspecific HS accumulation in MPS IIIB mouse brain

Immunofluorescence detection using a panel of five antiHS antibodies (HS4E4, EV3C3, HS4C3, AO4B08, $\mathrm{RB} 4 \mathrm{Ea}$ ) was performed on brain sections of adult MPS IIIB mice and their age-matched wt littermates (6-monthold, $n=6$ /group), to determine the distribution of HS containing different patterns of sulfation and their involvement in the lysosomal storage pathology in the CNS of MPS IIIB mice. These antibodies were obtained by phage display technology and characterized by previous studies as recognizing unique HS sulfation epitopes (Dennissen et al. 2002; Kurup et al. 2007; ten Dam et al. 2003, 2004, 2006; Thompson and Nowakowski 1991; Ulusoy et al. 2009; Valencia-Sanchez et al. 2006; Valiunas et al. 2005; van de Lest et al. 1994; van Kuppevelt et al. 1998, 2001; Wijnhoven et al. 2008). These antibodies bound differentially within the brains of the wt and MPS IIIB mice (Table 3; Fig. 1) and could be divided into two major categories based on their binding patterns (Table 3 ). The first group includes HS4E4, HS4C3, EV3C3 and AO4B08, which bound brain parenchymal cells and/or vasculature with differential intensity in wt versus MPS III mice. The second category includes only RB4Ea12, which exclusively stained brain parenchymal cells in both wt and MPS IIIB mouse brains, including all neurons and glial cells in white matter (Table 3, Fig. 1). The reaction of each antibody was observed throughout the brain, but with distinct cell type specificities. No staining was detected in the brains of either wt or MPS IIIB mice when using the control antibody MPB49.

In wt mouse brain, both HS4E4 and $\mathrm{HS} 4 \mathrm{C} 3$ reacted with brain parenchymal cells in grey matter and vasculature (Table 3; Fig. 1a, b), while EV3C3 and AO4B08 resulted in exclusive staining of blood vessels without visible staining in other cells (Table 3; Fig. 1a, b). While there were intensity differences (Table 4), the staining patterns of these four antibodies were relatively homogenous in wt mouse brain. In contrast, in MPS IIIB mouse, the staining with each of these antibodies was generally coarse and substantially increased in both brain cells and blood vessels (Table 3; Fig. 1a-d). We observed similar patterns of granulated staining by these four antibodies in neurons in cerebral cortex, thalamus, brain stem, and Purkinje cells (cerebellum) in MPS IIIB mouse brains (Fig. 1a-d). These granulated patterns of staining strongly suggest that these HS glycoforms, highly likely HS oligosaccharides, accumulate within the lysosomes in these cells. As such, HS glycoforms recognized by these antibodies are likely to reflect membrane-bound cell surface GAGs that are recycled through lysosomal pathways. Interestingly, none of these four antibodies reacted to the HS in hippocampal neurons (Table 3, data not shown), although hippocampal neurons are also known to 
Table 3 Differential anti-HS antibodies binding in mouse brain

\begin{tabular}{|c|c|c|c|c|c|c|c|c|c|c|c|}
\hline \multirow[t]{2}{*}{ Brain cells } & \multirow[t]{2}{*}{ LS-path } & \multicolumn{2}{|c|}{ HS4E4 } & \multicolumn{2}{|c|}{ HS4C3 } & \multicolumn{2}{|c|}{$\mathrm{EV} 3 \mathrm{C} 3$} & \multicolumn{2}{|c|}{ AO4B08 } & \multicolumn{2}{|c|}{ RB4Ea12 } \\
\hline & & wt & IIIB & wt & IIIB & wt & IIIB & wt & IIIB & wt & IIIB \\
\hline Endothelia & \pm & +++ & ++++ & + & $\geq++$ & ++ & $\geq+++$ & ++ & ++++ & - & - \\
\hline Neurons & & + & ++++ & + & $\geq+++$ & - & ++++ & - & ++++ & ++ & ++++ \\
\hline CTX & ${ }^{\mathrm{a}} \mathrm{Y}$ & + & $\mathrm{e}_{++++}$ & + & $\mathrm{d}_{++++}$ & - & $\mathrm{d}_{++++}$ & - & $\mathrm{d}_{++++}$ & ++ & ++++ \\
\hline $\mathrm{TH}$ & ${ }^{b} Y$ & + & $\mathrm{e}_{++++}$ & + & $\mathrm{e}_{++++}$ & - & $\mathrm{e}_{++++}$ & - & $\mathrm{e}_{++++}$ & ++ & ++++ \\
\hline HP & ${ }^{\mathrm{b}} \mathrm{Y}$ & - & - & - & - & - & - & - & - & ++ & ++++ \\
\hline BS-M & ${ }^{c} \mathrm{Y}$ & + & $\mathrm{d}_{++++}$ & + & $\mathrm{f}_{++++}$ & - & $\mathrm{e}_{++++}$ & - & $\mathrm{e}, \mathrm{f}_{++++}$ & ++ & ++++ \\
\hline BS-I & ${ }^{b, c} Y$ & + & $\mathrm{e}_{+++}$ & & $\mathrm{e}_{++++}$ & & $\mathrm{e}_{++++}$ & & $\mathrm{e}, \mathrm{f}_{++++}$ & ++ & ++++ \\
\hline CB-P & ${ }^{\mathrm{c}} \mathrm{Y}$ & + & $\mathrm{f}_{+++}$ & + & $\mathrm{f}_{++++}$ & - & $\mathrm{d}_{++++}$ & - & $\mathrm{f}_{++++}$ & ++ & ++++ \\
\hline $\mathrm{CB}-\mathrm{G}$ & $\mathrm{N}$ & - & - & - & - & - & - & - & - & ++ & ++++ \\
\hline WM-glia & $\mathrm{n} / \mathrm{a}$ & - & - & - & - & - & - & - & - & ++ & ++++ \\
\hline
\end{tabular}

Cryostat brain sections from wt $(n=4)$ and MPS IIIB $(n=4)$ mice were assayed for HS domains by immunofluorescence (IF) staining. $L S$-Path lysosomal storage pathology, $C T X$ cerebral cortex, $T H$ thalamus, $H P$ hippocampus, $B S-M$ ventral medullary retic nuclear of brain stem, $B S-I$ Intermediate reticular nuclei of brain stem, $C B-P$ cerebellum-Purkinje cells, $C B-G$ cerebellum-granular neurons, $W M$ white matters. Lysosomal storage pathology by toluidine blue staining: \pm : Majority endothelial cells do not exhibit lysosomal storage pathology; $Y$ exhibiting lysosomal storage pathology, $N$ no visible lysosomal storage pathology.+-++++: relative IF staining intensities observed under a fluorescent microscope, referring the intensity of HS4C3 stained wt endothelia and HS4E4 stained wt brain cells as +

${ }^{a}$ Fine foamy vesicles

${ }^{\mathrm{b}}$ Small vacuoles

${ }^{\mathrm{c}}$ Large vacuoles

Anti-HS antibody staining: ${ }^{d}$ Fine granules

${ }^{\mathrm{e}}$ Small granules

${ }^{\mathrm{f}}$ Coarse granules

exhibit lysosomal storage pathology (Li et al. 1999), indicating that the HS glycoforms in hippocampal neurons may be unique relative to the HS structures found in neurons in most other regions of the brain. Further, we did not observe staining by any one of these four antibodies in granular neurons in cerebellum (Table 3; Fig. 1), a group of neurons that do not exhibit lysosomal storage pathology (Fu et al. 2007; Li et al. 1999). In white matter, such as corpus callosum, all four antibodies bound only to the blood vessels, showing no staining of neuronal axons or glial cells (Table 3; Fig. 1ad). Blood vessel staining included both large blood vessels (arteries and veins) as well as capillaries. As capillaries lack smooth muscle, this suggests that blood vessel staining was likely to be present in endothelial cells. Blood vessel staining in MPS IIIB mouse brain was not only increased but also displayed coarse (but not granulated) features indicating pathologic changes in the vasculature (Fig. 1a-d).

In contrast to the staining pattern using the other four anti-HS antibodies, antibody RB4Ea exclusively stained cells within the brain parenchymal, including both neurons and glia, but not blood vessels. Although the intensity of RB4Ea staining in the brain was significantly higher in MPS IIIB mice than in wt mice (Fig. 1e; Table 4), it was homogeneous in target cells, in contrast to the coarsely punctuate patterns revealed by the other four antibodies. The increase in RB4Ea staining was seen in all neurons, including cerebella granular neurons, which, do not exhibit lysosomal storage pathology. Taken together, these data suggest that the increase of RB4Ea-specific HS glycoforms in MPS IIIB mouse brain may not result from increased lysosomal HS storage, since this antibody stains all neurons, including neurons with or without lysosomal storage pathology, in a pattern inconsistent with the presence of lysosomal GAG accumulation. It is therefore likely that this elevated HS expression results from specific changes in HS biosynthesis.

Elevated expression of genes encoding HS synthetic enzymes and FGFs in MPS IIIB brain

The distribution and increased expression of HS glycoforms in MPS IIIB mouse brain suggested that HS synthesis may be elevated, in addition to increased lysosomal storage of HS GAGs. To further assess HS biosynthesis, we performed qRT-PCR using the total RNA isolated from 1-month-old and 6-month-old mice $(n \geq 4 /$ group), targeting multiple genes that encode enzymes involved in synthesis of specific HS glycoforms, including 

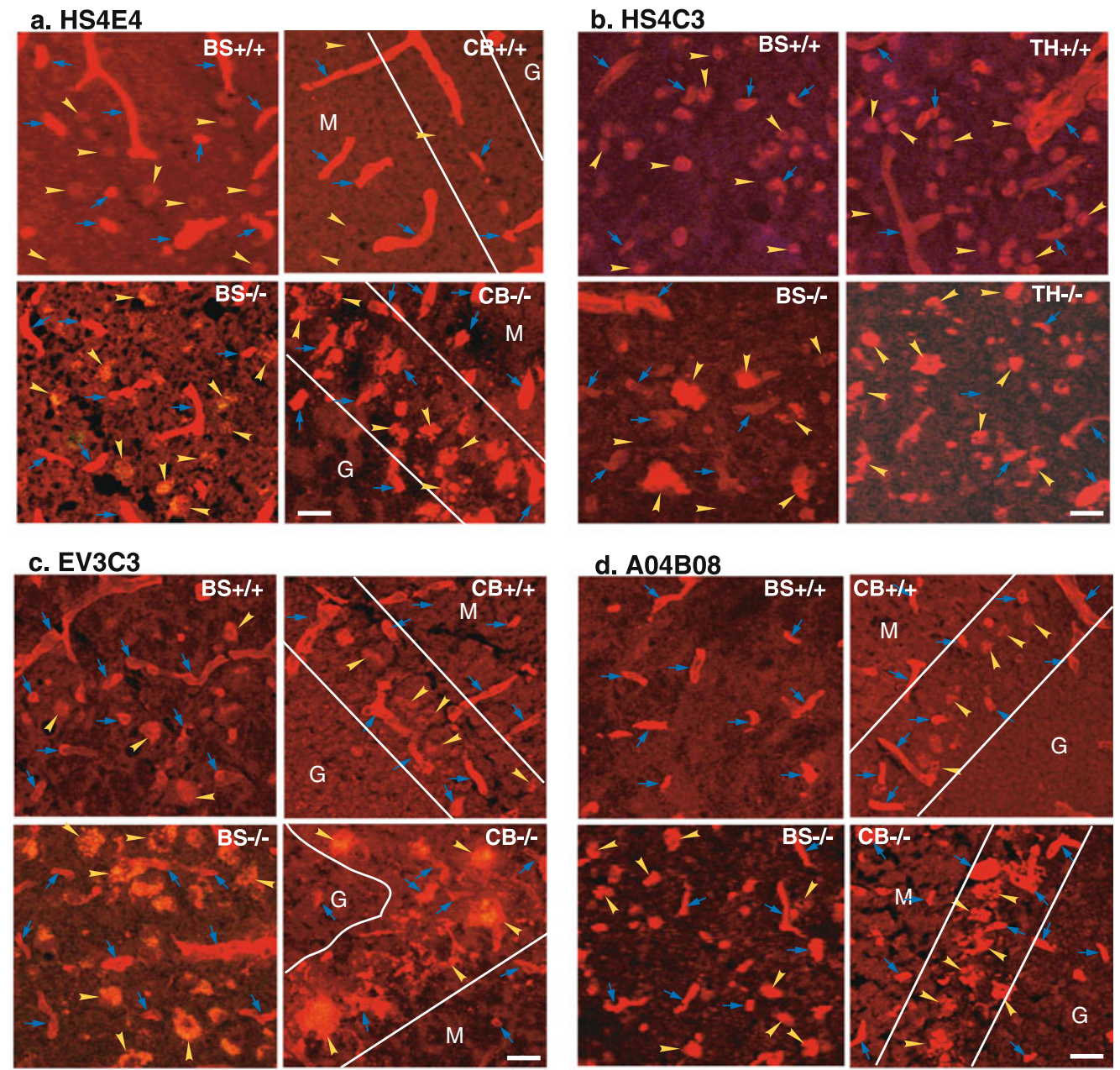

\section{e. RB4Ea}
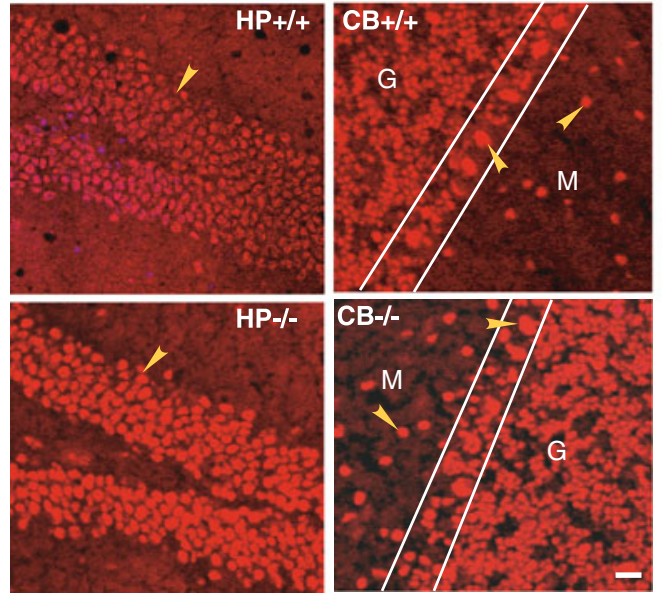

Fig. 1 Differential distribution of HS domains in the brains of wt and MPS IIIB mice. Cryostat brain sections $(10 \mu \mathrm{m})$ of 6-month-old wt and MPS IIIB mice were stained by immunofluorescence for specific HS domains using five antibodies targeting HS epitopes with different sulfation patterns: a HS4E4, b HS4C3, c EV3C3, d AO4B08, e RB4Ea.

\section{f. MPB49}

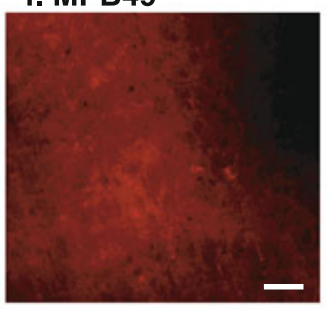

f MPB49 control. +/+ wt; -/- MPS IIIB, $B S$ brain stem; $C B$ cerebellum, $T H$ thalamus, $H P$ hippocampus. Yellow arrowheads: HS+ neurons. Blue arrows HS+ vasculature. $G$ granular layer, $M$ molecular layer; Purkinje cell layer (between two white lines). Scale bars: $20 \mu \mathrm{m}$ 
Table 4 Quantification of the increases in specific HS glycoforms in MPS IIIB mouse brain cells

\begin{tabular}{|c|c|c|c|c|c|c|c|c|c|c|}
\hline \multirow[t]{3}{*}{ Mice } & \multicolumn{10}{|c|}{ IF intensity (grey value) } \\
\hline & \multicolumn{2}{|l|}{ HS4E4 } & \multicolumn{2}{|l|}{$\mathrm{HS} 4 \mathrm{C} 3$} & \multicolumn{2}{|l|}{$\mathrm{EV} 3 \mathrm{C} 3$} & \multicolumn{2}{|c|}{ AO4B08 } & \multicolumn{2}{|l|}{ RB4Ea } \\
\hline & $\mathrm{BS}$ & $\mathrm{CB}$ & $\mathrm{BS}$ & $\mathrm{TH}$ & $\mathrm{BS}$ & $\mathrm{CB}$ & $\mathrm{BS}$ & $\mathrm{CB}$ & HP & $\mathrm{CB}$ \\
\hline$+/+$ & $130 \pm 8$ & $101 \pm 7$ & $105 \pm 16$ & $105 \pm 7$ & $134 \pm 20$ & $131 \pm 10$ & $\mathrm{n} / \mathrm{a}$ & $122 \pm 19$ & $122 \pm 14$ & $149 \pm 25$ \\
\hline$-1-$ & $168 \pm 19$ & $248 \pm 5$ & $238 \pm 10$ & $247 \pm 4$ & $236 \pm 26$ & $248 \pm 3$ & $248 \pm 4$ & $249 \pm 3$ & $245 \pm 2$ & $246 \pm 5$ \\
\hline
\end{tabular}

Quantitative analysis of IF images in Fig. 1. All non-vasculature IF signals were analyzed by manual thresholding using Image J software. Data here are the means $\pm \mathrm{SD} /$ unit (cell)

$+/+$ wt, $-/-$ MPS IIIB, $B S$ brain stem, $C B$ cerebellum, $T H$ thalamus, $H P$ hippocampus, $n / a$ no non-vasculature IF signal. IF intensity was significant between all compared groups $(P<0.01)$

NDST1-4 and GLCE, and the end product markers of GAG function, such as FGF1 and FGF2 (Table 5). We found a moderate but significant increase $(P<0.05)$ in most HS synthesis-related transcripts tested in whole MPS IIIB brain (compared to wt), with the exception of FGF1, at 1 month and 6 months of age (Table 5). Western blot probing FGF1 and FGF2 was carried out to further assess whether the disease alters the expression of these growth factor in the brain of 6-month-old mice, and showed a significant increase in both FGF1 and FGF2 proteins in MPS IIIB brain (Fig. 2). These results support our hypothesis that the lysosomal HS storage led to the elevation of HS biosynthesis and elevated HS and FGF expression, which may, in turn, exacerbate lysosomal storage pathology. It is important to note that many factors can be attributed to the disparity between FGF 1 mRNA and protein, such as the property of the primers used for qRT-PCR.

Table 5 Elevated expression of genes essential for HS biosynthesis in MPS IIIB mouse brains

\begin{tabular}{lcc}
\hline \multirow{2}{*}{ Genes } & \multicolumn{2}{c}{${ }^{\mathrm{a}} 2^{-\Delta \Delta \mathrm{Ct}}$ (fold of increase) } \\
\cline { 2 - 3 } & ${ }^{\mathrm{b}} 1 \mathrm{mo}$ & ${ }^{\mathrm{b}} 6 \mathrm{mo}$ \\
\hline NDST1 & 1.1 & ${ }^{\mathrm{c}} 1.7$ \\
NDST2 & ${ }^{\mathrm{c}} 1.4$ & ${ }^{\mathrm{c}} 1.8$ \\
NDST3 & ${ }^{\mathrm{c}} 1.7$ & ${ }^{\mathrm{c}} 2.1$ \\
NDST4 & ${ }^{\mathrm{c}} 2.0$ & ${ }^{\mathrm{c}} 1.6$ \\
GLCE & ${ }^{\mathrm{c}} 1.4$ & ${ }^{\mathrm{c}} 1.7$ \\
FGF1 & 0.9 & 1.0 \\
FGF2 & ${ }^{\mathrm{c}} 1.5$ & ${ }^{\mathrm{c}} 1.3$ \\
\hline
\end{tabular}

${ }^{a}$ qRT-PCR data was analyzes by means of the comparative threshold $(\mathrm{Ct})$ method and expressed as $2^{-\Delta \Delta C t}$ (fold of increase), relative quantitation of gene expression in the brain of MPS IIIB mice $(n=5)$ vs. wt mice $(n=4)$

${ }^{\mathrm{b}}$ The age of mice tested

${ }^{\mathrm{c}}$ The increases in gene expressions are significant $(P<0.05, \Delta \mathrm{Ct}$-MPS IIIB vs. $\Delta \mathrm{Ct}-\mathrm{wt})$

\section{Discussion}

While the accumulated GAGs in MPS disorders are welldescribed, it is unclear in most instances whether lack of lysosomal degradation leads to equivalent build-up of all glycan structures within a particular group or whether specific glycans preferentially accumulate in the lysosome. Moreover, while lack of glycan degradation clearly drives these diseases, possible compensatory up-regulation of biosynthesis, resulting from loss of glycan functions, could contribute to overall glycan burden and disease severity. Determining the relevance of these two issues is essential to determining whether therapies in addition to enzyme replacement would be of benefit in lysosomal storage disorders. Here we have used five anti-HS antibodies, each recognizing unique repertoire of different HS sulfation domains, to demonstrate for the first time a cell-typespecific and domain-specific distribution pattern of lysosomal HS storage in the CNS of MPS IIIB mice. It has been reported that the tissue distribution of HS sulfation epitopes is highly defined and tightly regulated (Dennissen et al. 2002). For example, in skeletal muscle a specific HS form, recognized by antibody RB4EA, is concentrated at the neuromuscular synapse while others are present throughout

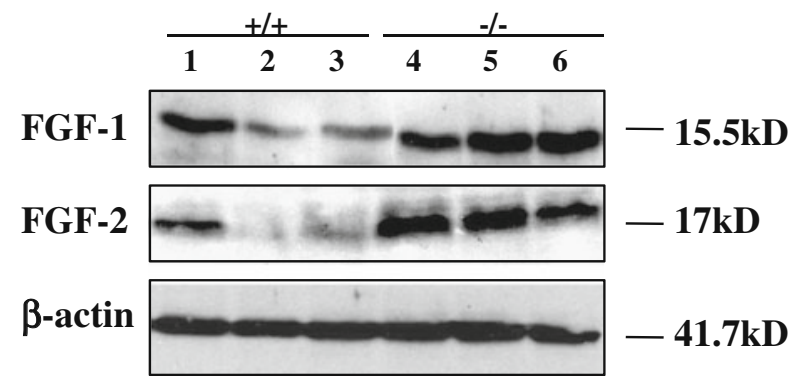

Fig. 2 Increase in the expression of FGF1 and FGF2 in MPS IIIB mouse brain. Whole cell proteins $(20 \mu \mathrm{g} / \mathrm{sample})$ isolated from the brain of 6-month-old mice were subjected to SDS-PAGE separation and western blotting for FGF1, FGF2, or beta actin control. FGF2. +/+ $1-3$ : wt $(n=3)$; -/- 4-6: MPS IIIB $(n=3)$ 
the muscle membrane (Jenniskens et al. 2002). Similarly, some antibodies to certain HS glycoforms stain the glomerular basement membrane of the kidney (HS4C3) but not the tubules (van Kuppevelt et al. 1998), while others (EV3C3) specifically stain the epithelial cells of lung bronchioli (Smits et al. 2004). Thus, each of the antibodies we have used shows specific tissue staining patterns and a specificity for binding to HS glycoforms. Consistent with this, our data reveals different intracellular and cell-type specific distribution patterns of HS domains, and that the same cell types can harbor multiple types of HS domains. Our data lead to two important findings. First, we have demonstrated the neuronal specificity of cell surface HS domains in mice. Second, we have found that the lysosomal HS storage may cause an increase in HS biosynthesis in MPS IIIB mouse brain, which may be an important factor that, in turn, exacerbates the HS accumulation.

Four of these five antibodies, HS4E4, HS4C3, EV3C3 and AO4B08, were shown to recognize HS in brain cells (predominantly neurons) and/or brain vasculature of both wt and MPS IIIB mice. The HS domains reacting with these antibodies are distributed homogenously in the CNS and blood vessel cells of the wt mouse brain. In contrast, in MPS IIIB mouse brain, these HS epitopes are quantitatively increased in neurons, with coarse and/or granulated distribution patterns correlating with the patterns of CNS lysosomal storage pathology in these animals. It is therefore highly likely that in these neurons the HS domains recognized by $\mathrm{HS} 4 \mathrm{E} 4, \mathrm{HS} 4 \mathrm{C} 3, \mathrm{EV} 3 \mathrm{C} 3$ and $\mathrm{AO} 4 \mathrm{~B} 08$ are membrane-bound cell surface GAGs, which normally recycle through lysosomes, and the increase in these HS epitopes in the CNS of MPS IIIB mice may be predominately due to the accumulation of undegraded or partially degraded HS GAGs in lysosomes of brain cells. Given the broad specificity of these antibodies for particular HS glycoforms, the relative uniform change in MPS IIIB brain staining for all four of these antibodies suggests that HS forms with 2-O-, 3-O-, and 6-O-sulfation and also $\mathrm{N}$-sulfated glucuronic acid accumulate in lysosomes in neurons. This conclusion is supported by the observation that none of these four antibodies reacted with HS in granular neurons in the cerebellum, which are a group of neurons that do not exhibit lysosomal storage pathology in MPS IIIB mice (Fu et al. 2007; Li et al. 1999). These data may be important for the further characterization of the nature and functional significance of neuronal surface HSPGs in the CNS. The specific HS domains may also have potential as therapeutic targets for MPS IIIB. Interestingly, while each of these four antibodies reacts with HS in the same cell-types between normal and MPS IIIB mouse brain, we observed Ab-specific lysosomal distribution patterns in MPS IIIB mouse brains, suggesting
HS domain-specific degradation pathways involving differential lysosomal trafficking.

While the increased abundance and aberrant distribution of HS domains targeted by HS4E4, HS4C3, EV3C 3 and AO4B08 occurs in the majority of neurons having lysosomal storage pathology, none of them recognized HS in hippocampal neurons, which are also known to manifest lysosomal storage pathology (unpublished data). The absence of these domains from this particular neuronal cell type is likely to be related to its function, and further studies in models such as this could provide a reliable method of associating different HS domains with specific cell-types in situ, which may advance our understanding of the roles of HSPG in neuronal functions. Further, these antibodies may be used to screen the stored specific HS domains in MPS IIIB and other types MPS III disorders that also manifest lysosomal HS storage as therapeutic targets for these diseases.

We also observed that HS4E4, HS4C3, EV3C3 and AO4B08 recognize the HS domains in both large blood vessels and capillaries in the brains of wt and MPS IIIB mice, although with increased intensity in the mutant animals. Previous studies showed that HS is found in the basement membrane of all vasculature and that these four antibodies bind to blood vessels in other organs (Dennissen et al. 2002; van Kuppevelt et al. 1998). Because endothelial cells are the sole constituents of capillary walls in somatic tissues, it is highly likely that the HS epitopes recognized by these four antibodies are normally harbored in endothelial cells. It is worth noting that majority of endothelial cells in MPS IIIB mouse brain do not manifest lysosomal storage pathology. Therefore, it is likely that HS4E4, HS4C3, EV3C3 and AO4B08-bound HS epitopes in the vasculatures are not GAGs recycled through lysosomal pathways, and the substantial increase of these HS epitopes in the CNS endothelial cells in MPS IIIB mouse brain may not be the consequence of lysosomal HS storage. These data also imply the functional-specificity of these HS glycoforms in different cell types.

While each of the four Abs discussed above revealed a coarse punctuate distribution of HS domains in neurons, consistent with lysosomal accumulation, the distinctly homogeneous cytoplasmic HS recognition pattern of antibody RB4Ea led to our hypothesis that the lysosomal HS accumulation may have secondary pathological impacts on glycosylation in the CNS of MPS IIIB mice. This antibody reacts exclusively with the HS domains in brain parenchymal cells, including all neurons and glia, but not vascular cells. That this antibody does not stain blood vessels has been previously reported in skeletal muscle, where it is concentrated specifically at the neuromuscular synapse and in intramuscular nerves (Jenniskens et al. 2000). The increase in RB4Ea staining in MPS IIIB mouse 
brain is homogenous in all of its target cells, including granular neurons in cerebellum, and this increased staining does not show patterns consistent with lysosomal storage pathology. While the exact natures of the HS epitopes these different antibodies bind to remain unclear, previous studies showed that the antibody-binding HS epitopes are likely to be complex of specific modifications (Dennissen et al. 2002; Kurup et al. 2007; Smits et al. 2006; Ten Dam et al. 2006). It is possible that RB4Ea12 binds preferentially to HS forms that may not be present as a trans-membrane GAGs on cell surfaces. This raises the question as to why it is over-represented in MPS IIIB brain cells, since it does not appear to depend on lysosomal degradation. We hypothesized that the elevation of RB4Ea, unlike elevation of glycoforms recognized by other four HS antibodies, is likely a consequence of enhanced HS biosynthesis, and this is supported by the up-regulation of multiple enzyme genes essential for HS biosynthesis, such as NDST1-4 and GLCE, as well as an increase in the expression of FGF1 and FGF2 in MPS IIIB mouse brain. Based on these findings, we suggest that the observed increase in HS biosynthesis is a compensatory response to the disruption of normal HS recycling in MPS IIIB cells. Once broken down in functional lysosomes, individual units of HS monosaccharides are typically transported from the lysosomal compartment into the cytoplasm, and reused in biosynthetic glycosylation pathways (Varki et al. 2008) In MPS IIIB mouse brain, the lysosomal storage of HS results in a shortage of HS to be reused for glycosylation, which then leads to the enhanced HS biosynthesis to compensate for such effects. Because we observed up-regulation of an HS moiety that was not lysosomal, we believe that the increase is non-preferential, possibly involving not only membranebound cell surface HS domains, but also intracellular and extra-cellular matrix HS epitopes. This is supported by the increase in HS4E4, HS4C3, EV3C3 and AO4B08-bound HS domains in endothelial cells in MPS IIIB mouse brain, while majority endothelial cells do not exhibit lysosomal HS storage pathology. Importantly, we have also demonstrated that the elevation of HS biosynthesis emerges early in the brain of MPS IIIB mice. Hence, it is highly likely to contribute to the neuropathology of the disease by exacerbating the lysosomal HS accumulation, which is supported by the report that high efficiency of GAG synthesis leads to a severe phenotype in patients with MPS IIIB, IIIA and II (Piotrowska et al. 2009). These HS biosynthesis pathways may therefore offer a specific target for MPS IIIB therapeutic development, by inhibiting the HS biosynthesis using small molecules as demonstrated in recent studies using rhodamine B in mice with MPS IIIA, another disease with lysosomal HS storage (Roberts et al. 2007; Roberts et al. 2006), or by gene silencing as shown in two most recent in vitro studies for MPS IIIA and MPS I
(Dziedzic et al. 2010; Kaidonis et al. 2010). This hypothesis is also supported by recent studies showing that genistein, a GAG synthesis inhibiting soy extract, can reduce lysosomal storage in vitro in MPS cell cultures (Jakobkiewicz-Banecka et al. 2009) and in MPS IIIB mice (Malinowska et al. 2009).

In summary, this is the first report of cell-specific and domain-specific lysosomal storage of HS in MPS IIIB mouse brains, and has led to the finding that the subsets of membrane-bound cell surface HS epitopes are neuronal type-specific in the CNS. We also demonstrated that lysosomal HS storage results in the increased expression of genes of multiple enzymes involved in HS biosynthesis in the CNS, which emerges early during disease progression, which may exacerbate the lysosomal storage pathology of MPS IIIB. These data may contribute substantially to mechanistic studies on the functions of specific HS domains in the CNS cells, leading to a better understanding of HS function and to the neuropathology of MPS IIIB, offering new potential targets for therapeutic development for MPS IIIB neuropathology.

Acknowledgement We would like to thank Cynthia McAllister of Morphology Core at NCHRI for her help in microscopy image process.

Conflict of interest The authors declare that they have no conflict of interest.

Open Access This article is distributed under the terms of the Creative Commons Attribution Noncommercial License which permits any noncommercial use, distribution, and reproduction in any medium, provided the original author(s) and source are credited.

\section{References}

Abramoff MD, Magelhaes PJ, Ram SJ (2004) Image processing with image. J Biophotonics Int 11:36-42

Beck M (2007) New therapeutic options for lysosomal storage disorders: enzyme replacement, small molecules and gene therapy. Hum Genet 121:1-22

Cearley CN, Wolfe JH (2007) A single injection of an adenoassociated virus vector into nuclei with divergent connections results in widespread vector distribution in the brain and global correction of a neurogenetic disease. J Neurosci 27:9928-9940

Cressant A, Desmaris N, Verot L, Brejot T, Froissart R, Vanier MT, Maire I, Heard JM (2004) Improved behavior and neuropathology in the mouse model of Sanfilippo type IIIB disease after adenoassociated virus-mediated gene transfer in the striatum. J Neurosci 24:10229-10239

Dennissen MA, Jenniskens GJ, Pieffers M, Versteeg EM, Petitou M, Veerkamp JH, van Kuppevelt TH (2002) Large, tissue-regulated domain diversity of heparan sulfates demonstrated by phage display antibodies. J Biol Chem 277:10982-10986

Desmaris N, Verot L, Puech JP, Caillaud C, Vanier MT, Heard JM (2004) Prevention of neuropathology in the mouse model of Hurler syndrome. Ann Neurol 56:68-76 
DiRosario J, Divers E, Wang C, Etter J, Charrier A, Jukkola P, Auer H, Best V, Newsom DL, McCarty DM, Fu H (2009) Innate and adaptive immune activation in the brain of MPS IIIB mouse model. J Neurosci Res 87:978-990

Dziedzic D, Wegrzyn G, Jakobkiewicz-Banecka J (2010) Impairment of glycosaminoglycan synthesis in mucopolysaccharidosis type IIIA cells by using siRNA: a potential therapeutic approach for Sanfilippo disease. Eur J Hum Genet 18:200-205

Esko JD, Selleck SB (2002) Order out of chaos: assembly of ligand binding sites in heparan sulfate. Annu Rev Biochem 71:435-471

Freeze H (2008) Genetic disorders of glycan degradation. In: Varki A, Cummings R, Esko J, Freeze H, Stanley P, Bertozzi C, Hart G, Etzler M (eds) Essentials of glycobiology, 2nd edn. Cold Spring Harbor Laboratory, New York, pp 567-583

Fu H, Samulski RJ, McCown TJ, Picornell YJ, Fletcher D, Muenzer J (2002) Neurological correction of lysosomal storage in a mucopolysaccharidosis IIIB mouse model by adeno-associated virus-mediated gene delivery. Mol Ther 5:42-49

Fu H, Kang L, Jennings JS, Moy SS, Perez A, Dirosario J, McCarty DM, Muenzer J (2007) Significantly increased lifespan and improved behavioral performances by rAAV gene delivery in adult mucopolysaccharidosis IIIB mice. Gene Ther 14:10651077

Fu H, DiRosario J, Kang L, Muenzer J, McCarty DM (2010) Restoration of central nervous system alpha- $\mathrm{N}$-acetylglucosaminidase activity and therapeutic benefits in mucopolysaccharidosis IIIB mice by a single intracisternal recombinant adeno-associated viral type 2 vector delivery. J Gene Med 12:624-633

Heuer GG, Passini MA, Jiang K, Parente MK, Lee VM, Trojanowski JQ, Wolfe JH (2002) Selective neurodegeneration in murine mucopolysaccharidosis VII is progressive and reversible. Ann Neurol 52:762-770

Jakobkiewicz-Banecka J, Piotrowska E, Narajczyk M, Baranska S, Wegrzyn G (2009) Genistein-mediated inhibition of glycosaminoglycan synthesis, which corrects storage in cells of patients suffering from mucopolysaccharidoses, acts by influencing an epidermal growth factor-dependent pathway. J Biomed Sci 16:26

Jenniskens GJ, Oosterhof A, Brandwijk R, Veerkamp JH, van Kuppevelt TH (2000) Heparan sulfate heterogeneity in skeletal muscle basal lamina: demonstration by phage display-derived antibodies. J Neurosci 20:4099-4111

Jenniskens GJ, Hafmans T, Veerkamp JH, van Kuppevelt TH (2002) Spatiotemporal distribution of heparan sulfate epitopes during myogenesis and synaptogenesis: a study in developing mouse intercostal muscle. Dev Dyn 225:70-79

Kaidonis X, Liaw WC, Roberts AD, Ly M, Anson D, Byers S (2010) Gene silencing of EXTL2 and EXTL3 as a substrate deprivation therapy for heparan sulphate storing mucopolysaccharidoses. Eur J Hum Genet 18:194-199

Killedar S, Dirosario J, Divers E, Popovich PG, McCarty DM, Fu H (2010) Mucopolysaccharidosis IIIB, a lysosomal storage disease, triggers a pathogenic CNS autoimmune response. J Neuroinflammation 7:39

Kurai T, Hisayasu S, Kitagawa R, Migita M, Suzuki H, Hirai Y, Shimada T (2007) AAV1 mediated co-expression of formylglycinegenerating enzyme and arylsulfatase a efficiently corrects sulfatide storage in a mouse model of metachromatic leukodystrophy. Mol Ther 15:38-43

Kurup S, Wijnhoven TJ, Jenniskens GJ, Kimata K, Habuchi H, Li JP, Lindahl U, van Kuppevelt TH, Spillmann D (2007) Characterization of anti-heparan sulfate phage display antibodies AO4B08 and HS4E4. J Biol Chem 282:21032-21042

Lensen JF, Rops AL, Wijnhoven TJ, Hafmans T, Feitz WF, Oosterwijk E, Banas B, Bindels RJ, van den Heuvel LP, van der Vlag J, Berden JH, van Kuppevelt TH (2005) Localization and functional characterization of glycosaminoglycan domains in the normal human kidney as revealed by phage displayderived single chain antibodies. J Am Soc Nephrol 16:12791288

Li HH, Yu WH, Rozengurt N, Zhao HZ, Lyons KM, Anagnostaras S, Fanselow MS, Suzuki K, Vanier MT, Neufeld EF (1999) Mouse model of Sanfilippo syndrome type B produced by targeted disruption of the gene encoding alpha-N-acetylglucosaminidase. Proc Natl Acad Sci USA 96:14505-14510

Li HH, Zhao HZ, Neufeld EF, Cai Y, Gomez-Pinilla F (2002) Attenuated plasticity in neurons and astrocytes in the mouse model of Sanfilippo syndrome type B. J Neurosci Res 69:30-38

Liu G, Martins I, Wemmie JA, Chiorini JA, Davidson BL (2005) Functional correction of CNS phenotypes in a lysosomal storage disease model using adeno-associated virus type 4 vectors. J Neurosci 25:9321-9327

Livak KJ, Schmittgen TD (2001) Analysis of relative gene expression data using real-time quantitative PCR and the 2(-Delta Delta C (T)) method. Methods 25:402-408

Malinowska M, Wilkinson FL, Bennett W, Langford-Smith KJ, O'Leary HA, Jakobkiewicz-Banecka J, Wynn R, Wraith JE, Wegrzyn G, Bigger BW (2009) Genistein reduces lysosomal storage in peripheral tissues of mucopolysaccharide IIIB mice. Mol Genet Metab

McCarty DM, Dirosario J, Gulaid K, Muenzer J, Fu H (2009) Mannitol-facilitated CNS entry of rAAV2 vector significantly delayed the neurological disease progression in MPS IIIB mice. Gene Ther

McGlynn R, Dobrenis K, Walkley SU (2004) Differential subcellular localization of cholesterol, gangliosides, and glycosaminoglycans in murine models of mucopolysaccharide storage disorders. J Comp Neurol 480:415-426

Neufeld EF, Muenzer J (2001) The mucopolysaccharidoses. In: Scriver CR, Beaudet AL, Sly WS, Valle D (eds) The metabolic $\&$ molecular basis of inherited disease, 8th edn. McGraw-Hill, New York, pp 3421-3452

Ohmi K, Greenberg DS, Rajavel KS, Ryazantsev S, Li HH, Neufeld EF (2003) Activated microglia in cortex of mouse models of mucopolysaccharidoses I and IIIB. Proc Natl Acad Sci USA 100:1902-1907

Ohmi K, Kudo LC, Ryazantsev S, Zhao HZ, Karsten SL, Neufeld EF (2009) Sanfilippo syndrome type B, a lysosomal storage disease, is also a tauopathy. Proc Natl Acad Sci USA 106:8332-8337

Piotrowska E, Jakobkiewicz-Banecka J, Tylki-Szymanska A, Czartoryska B, Wegrzyn A, Wegrzyn G (2009) Correlation between severity of mucopolysaccharidoses and combination of the residual enzyme activity and efficiency of glycosaminoglycan synthesis. Acta Paediatr 98:743-749

Roberts AL, Thomas BJ, Wilkinson AS, Fletcher JM, Byers S (2006) Inhibition of glycosaminoglycan synthesis using rhodamine B in a mouse model of mucopolysaccharidosis type IIIA. Pediatr Res 60:309-314

Roberts AL, Rees MH, Klebe S, Fletcher JM, Byers S (2007) Improvement in behaviour after substrate deprivation therapy with rhodamine B in a mouse model of MPS IIIA. Mol Genet Metab 92:115-121

Rops AL, van den Hoven MJ, Baselmans MM, Lensen JF, Wijnhoven TJ, van den Heuvel LP, van Kuppevelt TH, Berden JH, van der Vlag J (2008) Heparan sulfate domains on cultured activated glomerular endothelial cells mediate leukocyte trafficking. Kidney Int 73:52-62

Ryazantsev S, Yu WH, Zhao HZ, Neufeld EF, Ohmi K (2007) Lysosomal accumulation of SCMAS (subunit $\mathrm{c}$ of mitochondrial ATP synthase) in neurons of the mouse model of mucopolysaccharidosis III B. Mol Genet Metab 90:393-401

Sands MS, Haskins ME (2008) CNS-directed gene therapy for lysosomal storage diseases. Acta Paediatr Suppl 97:22-27 
Sferra TJ, Qu G, McNeely D, Rennard R, Clark KR, Lo WD, Johnson PR (2000) Recombinant adeno-associated virus-mediated correction of lysosomal storage within the central nervous system of the adult mucopolysaccharidosis type VII mouse. Hum Gene Ther 11:507-519

Smits NC, Robbesom AA, Versteeg EM, van de Westerlo EM, Dekhuijzen PN, van Kuppevelt TH (2004) Heterogeneity of heparan sulfates in human lung. Am J Respir Cell Mol Biol 30:166-173

Smits NC, Lensen JF, Wijnhoven TJ, Ten Dam GB, Jenniskens GJ, van Kuppevelt TH (2006) Phage display-derived human antibodies against specific glycosaminoglycan epitopes. Methods Enzymol 416:61-87

ten Dam GB, Hafmans T, Veerkamp JH, van Kuppevelt TH (2003) Differential expression of heparan sulfate domains in rat spleen. $\mathrm{J}$ Histochem Cytochem 51:727-739

ten Dam GB, van de Westerlo EM, Smetsers TF, Willemse M, van Muijen GN, Merry CL, Gallagher JT, Kim YS, van Kuppevelt TH (2004) Detection of 2-O-sulfated iduronate and $\mathrm{N}$-acetylglucosamine units in heparan sulfate by an antibody selected against acharan sulfate (IdoA2S-GlcNAc)n. J Biol Chem 279:38346-38352

Ten Dam GB, Kurup S, van de Westerlo EM, Versteeg EM, Lindahl U, Spillmann D, van Kuppevelt TH (2006) 3-O-sulfated oligosaccharide structures are recognized by anti-heparan sulfate antibody HS4C3. J Biol Chem 281:4654-4662

Thompson JN, Nowakowski RW (1991) Enzymatic diagnosis of selected mucopolysaccharidoses: Hunter, Morquio type A, and Sanfilippo types A, B, C, and D, and procedures for measurement of 35SO4-glycosaminoglycans. In: Hommes FA (ed) Techniques in diagnostic human biochemical genetics - a laboratory manual. Wiley-Liss, New York, pp 567-586

Ulusoy A, Sahin G, Bjorklund T, Aebischer P, Kirik D (2009) Dose optimization for long-term rAAV-mediated RNA interference in the nigrostriatal projection neurons. Mol Ther 17:1574-1584

Valencia-Sanchez MA, Liu J, Hannon GJ, Parker R (2006) Control of translation and mRNA degradation by miRNAs and siRNAs. Genes Dev 20:515-524

Valiunas V, Polosina YY, Miller H, Potapova IA, Valiuniene L, Doronin S, Mathias RT, Robinson RB, Rosen MR, Cohen IS,
Brink PR (2005) Connexin-specific cell-to-cell transfer of short interfering RNA by gap junctions. J Physiol 568:459-468

van de Lest CH, Versteeg EM, Veerkamp JH, van Kuppevelt TH (1994) Quantification and characterization of glycosaminoglycans at the nanogram level by a combined azure A-silver staining in agarose gels. Anal Biochem 221:356-361

van Kuppevelt TH, Dennissen MA, van Venrooij WJ, Hoet RM, Veerkamp JH (1998) Generation and application of type-specific anti-heparan sulfate antibodies using phage display technology. Further evidence for heparan sulfate heterogeneity in the kidney. J Biol Chem 273:12960-12966

van Kuppevelt TH, Jenniskens GJ, Veerkamp JH, ten Dam GB, Dennissen MA (2001) Phage display technology to obtain antiheparan sulfate antibodies. Methods Mol Biol 171:519-534

Varki A, Esko J, Colly K (2008) Cellular organization of glycosylation. In: Varki A, Cummings R, Esko J, Freeze HS, Stanley P, Bertozzi C, Hart C, Etzler M (eds) Essentials of glycobiology, 2nd edn. CSH, New York, pp 37-46

Villani GR, Gargiulo N, Faraonio R, Castaldo S, Gonzalez YRE, Di Natale P (2007) Cytokines, neurotrophins, and oxidative stress in brain disease from mucopolysaccharidosis IIIB. J Neurosci Res $85: 612-622$

Walkley SU (2007) Pathogenic mechanisms in lysosomal disease: a reappraisal of the role of the lysosome. Acta Paediatr Suppl 96:26-32

Wijnhoven TJ, van de Westerlo EM, Smits NC, Lensen JF, Rops AL, van der Vlag J, Berden JH, van den Heuvel LP, van Kuppevelt TH (2008) Characterization of anticoagulant heparinoids by immunoprofiling. Glycoconj J 25:177-185

Yogalingam G, Hopwood JJ (2001) Molecular genetics of mucopolysaccharidosis type IIIA and IIIB: diagnostic, clinical, and biological implications. Hum Mutat 18:264-281

Zheng Y, Ryazantsev S, Ohmi K, Zhao HZ, Rozengurt N, Kohn DB, Neufeld EF (2004) Retrovirally transduced bone marrow has a therapeutic effect on brain in the mouse model of mucopolysaccharidosis IIIB. Mol Genet Metab 82:286-295 